\title{
Polybrominated diphenyl ethers and traditional organochlorine pollutants in fulmars (Fulmarus glacialis) from the Faroe Islands
}

\section{Citation}

Fängström, Britta, Maria Athanasiadou, Ioannis Athanassiadis, Anders Bignert, Philippe Grandjean, Pál Weihe, and Åke Bergman. 2005. “Polybrominated Diphenyl Ethers and Traditional Organochlorine Pollutants in Fulmars (Fulmarus Glacialis) from the Faroe Islands." Chemosphere 60 (7) (August): 836-843. doi:10.1016/j.chemosphere.2005.01.065.

\section{Published Version}

doi:10.1016/j.chemosphere.2005.01.065

\section{Permanent link}

http://nrs.harvard.edu/urn-3:HUL.InstRepos:34786605

\section{Terms of Use}

This article was downloaded from Harvard University's DASH repository, and is made available under the terms and conditions applicable to Other Posted Material, as set forth at http:// nrs.harvard.edu/urn-3:HUL.InstRepos:dash.current.terms-of-use\#LAA

\section{Share Your Story}

The Harvard community has made this article openly available.

Please share how this access benefits you. Submit a story.

Accessibility 


\title{
Polybrominated diphenyl ethers and traditional organochlorine pollutants in fulmars (Fulmarus glacialis) from the Faroe Islands
}

\author{
Britta Fängström*, Maria Athanasiadou, Ioannis Athanassiadis, Anders Bignert ${ }^{1}$, \\ Philippe Grandjean ${ }^{2,3}$, Pál Weihe ${ }^{2,4}$ and Åke Bergman
}

\author{
Department of Environmental Chemistry, Stockholm University, SE-106 91 Stockholm, Sweden; \\ ${ }^{1}$ Contaminant Research Group, Swedish Museum of Natural History, SE-104 05 Stockholm Sweden; \\ ${ }^{2}$ Institute of Public Health, University of Southern Denmark, DK-5000 Odense, Denmark; \\ ${ }^{3}$ Department of Environmental Health, Boston University School of Public Health, Boston, MA 02118, USA; \\ ${ }^{4}$ Faroese Hospital System, FR-100 Tórshavn, Faroe Islands
}

\begin{abstract}
The observed high-level burdens of organohalogens among the residents of the Faroe Islands, needs to be explained. Long-finned pilot whale (Globicephala melas) blubber and meat are known sources of environmental exposure. The present study focus on the organohalogen contamination of the fulmar (Fulmarus glacialis). The compounds quantified in fulmar muscle, fat, and egg are PCBs, DDTs, hexachlorobenzene (HCB), and polybrominated diphenyl ethers (PBDEs). The dominating pollutants are the 4,4'-DDT metabolite 4,4'-DDE and the two PCB congeners, CB-153 and CB-180, which are present in geometric mean concentrations of 7100,4700 and $2500 \mathrm{ng} / \mathrm{g}$ lipid weight (l.w.), respectively, in adult fulmar muscle. 4,4'-DDT and HCB concentrations are approximately $250 \mathrm{ng} / \mathrm{g}$ 1.w., each. Concentrations in the eggs are about $50 \%$ of the fulmar muscle levels, due to differences in lipid amounts, $4 \%$ in muscle and $10 \%$ in the eggs, the exposure contribution on a fresh weight basis is almost the same. As a result, both the egg and the adult fulmar muscle may lead to a significant exposure risk, if consumed by humans.

BDE-153, the most abundant PBDE congener in fulmar muscle, with a geometric mean concentration of $6.5 \mathrm{ng} / \mathrm{g}$ l.w., is much lower than the individual PCB congeners and 4,4'-DDE concentrations. In the adult fulmar muscle, the relative PBDE congener pattern is different from that previously observed in biota, with BDE-153 and BDE-154 as the dominating congeners, rather than BDE-47. In contrast, BDE-47 is the most abundant congener in juvenile muscle and subcutaneous fat. The $\Sigma$ PBDE concentrations are almost the same in egg, muscle (adult and juvenile) and subcutaneous fat (juvenile). For the polybrominated biphenyl (BB-153) the concentrations are considerably higher in the adult bird and egg than in the juvenile bird; this is also seen for the PCB and 4,4'-DDE concentrations.

PCB concentrations found in fulmar egg and muscle are in the same range as seen in the pilot whale, i.e. 590-5700 ng/g 1.w. for CB-153. Hence humans are also exposed to PCBs at a reasonable degree via intake of fulmar and/or fulmar egg and not only via pilot whale blubber.
\end{abstract}

Keywords: PBDE, PCB, egg, muscle,

*Corresponding author: e-mail: britta.fangstrom@mk.su.se 


\section{Introduction}

The Faroe Islands are located in the North Atlantic, far-away from known point sources of organohalogen contaminants. High trophic-level marine species, like whales and seabirds, have all been shown to contain rather high concentrations of organohalogen substances (OHS) like polychlorinated biphenyls (PCBs), 2,2-bis(4-chlorophenyl)-1,1-dichloroethene (4,4'DDE) and polybrominated diphenyl ethers (PBDEs) (Dam and Bloch, 2000; Fängström et al., 2004; Lindström et al., 1999). The pilot whales constitute an important part of the traditional diet, with PCB and PBDE concentrations ranging between 5-24 $\mu \mathrm{g} / \mathrm{g}$ lipid weight (1.w.) and 1-3 $\mu \mathrm{g} / \mathrm{g}$ 1.w., respectively (Dam and Bloch, 2000; Lindström et al., 1999). Besides the pilot whale, the Faroese eat local seabirds, such as fulmars (Fulmarus glacialis), and their eggs in considerable numbers.

PBDE concentrations have been extensively studied in humans, other mammals, fish, and birds (Hites, 2004). In pooled guillemot egg samples from the Baltic Proper, PBDE concentrations have shown a rapid increase from the late 1970s to the early 1980s (de Wit, 2002; Sellström et al., 1993). The increase in PBDE concentrations in the guillemot egg was followed by a decrease starting in 2000 (Sellström et al., 2003). This is probably due to the awareness of PBDEs as persistent pollutants, and, accordingly, voluntary changes in the use of PBDEs in countries such as Sweden and Japan. In North America, the PBDE concentrations are still increasing, as seen both in herring gull eggs and in human serum (Hites, 2004; Norstrom et al., 2002; Sjödin et al., 2003). From 1981 to 2000, the PBDE concentrations in herring gull eggs from the Great Lakes increased 20-75-fold, mainly due to the tetra- and penta-BDE congeners, BDE-47, BDE-100 and BDE-99 (Norstrom et al., 2002).

The concentrations of PCBs and 4,4'-DDE in guillemot eggs, from the Baltic Proper, have decreased since the 1970s (Bignert et al., 1995). Likewise, a time trend study of PCB and 4,4'-DDE levels in seabird eggs from the Canadian Arctic shows the overall trend for OHS is declining or, in some cases, shows no significant change in concentrations from 1975 to 1998 (Braune et al., 2001).

In remote arctic areas, the PCB concentrations in whales, seals and seabirds are in the ppm range, while the PBDE concentrations are still in the ppb range. (Law et al., 2003). However, the PBDEs in wildlife in the arctic have shown an exponential increase from 1981 to 2000 (Ikonomou et al., 2002). The origin of OHS in Arctic biota seems to be due longrange atmospheric or sea current transport (Law et al., 2003; Vorkamp et al., 2004a; Vorkamp et al., 2004b; Wania, 2003). The degree of deposition is dependent on the different OHS's physical-chemical properties and the environment they encounter (Wania and Mackay, 1996). In a study of atmospheric transport of PCBs and PBDEs, it has been shown that airborne PCBs were mainly found in the gaseous phase, while most of the PBDEs were detected adsorbed to particles. PBDEs were therefore more effectively removed from the atmosphere by precipitation than the PCBs (ter Schure et al., 2004).

The fulmar is a widely occurring seabird with a food intake mainly consisting of fish, fish viscera, and carrion. Egg contamination reflects the OHS body burden of the parent bird (Braune et al., 2001). The aim of the present study is to determine concentrations of PCBs, 4.4'-DDT, 4,4'-DDE and PBDEs in muscle of adult and juveniles, subcutaneous fat of juveniles and eggs, collected in 2000 and 2001 in the Faroe Islands, to produce baseline observations with possible relevance to future human exposure assessments in the Faroe Islands. 


\section{Material and methods}

\section{Sample collection}

Fulmars (Fulmarus glacialis) and fulmar eggs were collected in the Faroe Islands. Collection month and year, area, number of samples, and sex were recorded and given in Table 1. The samples collected were intended to represent a typical consumer choice. The samples were prepared at the Swedish Museum of Natural History. The fulmar muscle and subcutaneous fat were prepared and divided into portions of $1 \mathrm{~g}$ and half a gram, respectively. The egg content was removed through a hole drilled in the shell. The yolk and egg white were homogenized and divided into $1 \mathrm{~g}$ portions. All samples were frozen at $-20^{\circ} \mathrm{C}$, until taken out for analysis.

Table 1. Muscle, subcutaneous fat and eggs from Fulmars were collected at the Faroe Islands: matrix, collection year and month, area, number of samples and sex are given in the table; $\mathrm{F}=$ Female, $\mathrm{M}=$ Male, $\mathrm{O}=$ Sex unknown

\begin{tabular}{lllll}
\hline Matrix & Collection year/month & Area & $\mathrm{n}$ & $\mathrm{F} / \mathrm{M} / \mathrm{O}$ \\
\hline Egg & 2000/May & Skudoy & 9 & \\
& 2001/May & Hestur & 10 & \\
Muscle & & & & \\
Adult & 2000/November & & 10 & $3 / 7$ \\
Adult & 2001/August & Norderoerna & 5 & $1 / 4$ \\
Juvenile & 2000/August & Sudero & 9 & $-/ 5 / 4$ \\
Subcutaneous fat, juvenile & 2000/August & Sudero & 9 & $-/ 5 / 4$ \\
\hline
\end{tabular}

Chemicals: The pesticide standards, hexachlorobenzene (HCB), 2,2-bis(4-chlorophenyl)-1,1dichloroethene (4,4'-DDE), 2,2-bis(4-chlorophenyl)-1,1,1-trichloroethane (4,4'-DDT) and the individual PCB congeners (numbered according to (Ballschmiter et al., 1993) CB-53, CB101, CB-105, CB-118, CB-128, CB-138, CB-153, CB-156, CB-170, CB-180, CB-183 and CB-200 were purchased from Larodan Fine chemicals AB, Malmö, Sweden). The individual PBDE congeners (also numbered according to (Ballschmiter et al., 1993) BDE-47, BDE-77 BDE-99, BDE-100, BDE-138, BDE-153, BDE-154 and BDE-209 were synthesized in house (Marsh et al., 1999; Örn et al., 1996)). All solvents were of pesticide analysis quality. Methyl tert-butyl ether (HPLC-grade; Rathburn, Walkerburn, Scotland) was glass-distillated prior to use. Silica gel $(<0.063 \mathrm{~mm})$ was purchased from Macherey-Nagel (Duren, Germany) and activated before use. Deionized water was produced in an Elga stat (Elga Ltd, UK).

Instruments: Gas chromatography/mass spectrometry (GC/MS) was performed utilising a Finnigan TSQ 700 instrument (ThermoFinnigan, Bremen, Germany) connected to a Varian 3400 gas chromatograph equipped with a AS200S CTC autosampler. The transfer line temperature was set to $290^{\circ} \mathrm{C}$ and the ion source temperature maintained at $200^{\circ} \mathrm{C}$. Oncolumn injections were made using a septum equipped temperature programmable injector (SPI) fitted with a high performance insert directly connected to a DB-5 HT capillary column $(15 \mathrm{~m} \times 0.25 \mathrm{~mm}$ i.d., $0.1 \mu \mathrm{m}$ film thickness; J\&W Scientific) with helium as carrier gas at a head pressure of $3 \mathrm{psi}$. The injector was temperature programmed from $60^{\circ} \mathrm{C}$ to $320^{\circ} \mathrm{C}$ at $150^{\circ} \mathrm{C} / \mathrm{min}$ and the oven from $80^{\circ} \mathrm{C}(1 \mathrm{~min}), 15^{\circ} \mathrm{C} / \mathrm{min}$ to $300^{\circ} \mathrm{C}(16 \mathrm{~min})$. The PBDE congeners were analysed with selected ion monitoring (SIM) by scanning for the negative bromide ion (isotopes $\mathrm{m} / \mathrm{z} 79$ and 81 ) formed by electron capture reactions during chemical ionization (ECNI) with methane (5.0, AGA, Stockholm, Sweden) as the electron thermalization buffer gas was at 5.6 torr and a primary electron energy of $70 \mathrm{eV}$. The analyses of the coeluting substances BDE-154 and BB-153 were performed on a Finnigan SSQ 710 
instrument with the exact same instrumental parameters and modes as above. The substances were differentiated from each other by scanning for the negative ion isotopes $\mathrm{m} / \mathrm{z} 159$ and 161 [HBr $\left._{2}\right]^{-}$for BDE-154 and $m / z \quad 626$ and $628[\mathrm{M}+4]^{-},[\mathrm{M}+6]^{-}$for $2,2^{\prime}, 4,4^{\prime}, 5,5^{\prime}-$ hexabromobiphenyl (BB-153). All chromatographic data were collected, analysed and quantified using the proprietary ICIS2 software from Thermofinnigan.

Analysis by gas chromatography (GC) was performed on a Varian 3400 gas chromatograph, equipped with a Varian 8200 autosampler (Varian Associates, Walnut Creek, CA, USA), an electron capture detector (ECD), and a split-splitless injector operated in the splitless mode. Hydrogen was used as carrier gas and nitrogen as a make-up gas. For PCB and pesticide analysis, a DB-5 column $(30 \mathrm{~m} \times 0.25 \mathrm{~mm}$ i.d. and $0.25 \mu \mathrm{m}$ film thickness; J\& W Scientific, Folsom, CA, USA) was used. The column temperature was: $80^{\circ} \mathrm{C}(2 \mathrm{~min})$, $10^{\circ} \mathrm{C} / \mathrm{min}$ to $300^{\circ} \mathrm{C}(10 \mathrm{~min})$. The injector temperature was $250^{\circ} \mathrm{C}$ and the detector temperature $360^{\circ} \mathrm{C}$. The data were collected and processed using a PC-based ELDS Pro v2.0 system (Chromatograhic Data System AB, Stockholm, Sweden).

Clean up procedure: Fulmar muscle and subcutaneous fat samples ( $1 \mathrm{~g}$ and $0.5 \mathrm{~g}$, respectively) were homogenized with an IKA T25 homogenizer (Labassco AB, Partille, Sweden) in n-hexane:acetone (2:5) and extracted with n-hexane:MTBE (9:1) in an downscaled version of a previously described method (Jensen et al., 1983). The surrogate standards, CB-200 (20 ng and $200 \mathrm{ng}$, respectively) and BDE-138 (2 ng), was added, and the extractable lipids were then determined gravimetrically. The samples were treated with concentrated sulfuric acid to remove the bulk of lipids, followed by an additional clean up step to obtain lipid free samples. This was done on a column containing $1 \mathrm{~g}$ silica gel impregnated with sulfuric acid, $(2: 1, \mathrm{w}: \mathrm{w})$ with $\mathrm{n}$-hexane $(10 \mathrm{ml})$ as the mobile phase. The PCB/pesticide and PBDE were separated on a column of activated silica gel $(0.9 \mathrm{~g})$; the PCB congeners were eluted first with hexane $(5 \mathrm{ml})$ and the PBDEs were eluted in a subsequent dichloromethane (DCM) $(8 \mathrm{ml})$ fraction. Recoveries of the internal standards were determined by addition of injection standards for the PCB fraction (CB-53) and for the PBDE fraction (BDE-77).

The fulmar egg samples $(1 \mathrm{~g})$ were treated similarly to the muscle samples. The homogenization step was excluded since the eggs were homogenized at the time of sample preparation. The surrogate standards, CB-200 (100 ng) and BDE-138 (2 ng), was added prior the extraction.

Procedure solvent blank samples representing every fourth sample were cleaned up and analyzed in the same way as the other samples. The overall recoveries and standard deviation (SD) of the different surrogate standards for egg, muscle, and subcutaneous fat were $98 \pm$ $3.5 \%, 98 \pm 3.6 \%$ and $95 \pm 5.8 \%$, respectively, for CB-200 and $116 \pm 11 \%, 90 \pm 12 \%$ and $86 \pm$ $12 \%$, respectively, for BDE- 138 .

Statistical methods: Many of the measured contaminants showed significant right skewed distributions despite the relatively few samples. This is usually the case for these kinds of data (Esmen and Hammond, 1977). Although log-transformation eliminated most of the skew, heteroscedasticity was still present between the various matrices for several contaminants using Bartlett's test of homogeneity of variances. Therefore a non-parametric multiple comparisons test described in (Sokal and Rohlf, 1981) was applied to test differences between various tissues. 
Table 2. Concentrations (ng/g lipid weight) of five polybrominated diphenyl ethers (PBDEs) congeners, $\Sigma$ PBDE and BB-153 in egg, muscle and subcutaneous fat from fulmars collected at the Faroe Islands: the geometric mean (GM), $95 \%$ confidence interval (c.i.) and ranges are given.

\begin{tabular}{|c|c|c|c|c|c|c|c|c|c|c|c|c|}
\hline & \multicolumn{3}{|c|}{$\begin{array}{c}\text { Fulmar egg } \\
(\mathrm{n}=19)\end{array}$} & & Adult $(n=14$ & Fulma & uscle & dvenile $(n=9$ & & \multicolumn{3}{|c|}{$\begin{array}{l}\text { Fulmar subcutaneous fat } \\
\text { Juvenile }(\mathrm{n}=9)\end{array}$} \\
\hline & GM & $95 \%$ c.i. & range & GM & $95 \%$ c.i. & range & GM & $95 \%$ c.i. & range & GM & $95 \%$ c.i. & range \\
\hline Lipid amount (\%) & 10 & $9.9-11$ & $9.1-11$ & 4.3 & $3.8-4.8$ & $3.0-5.8$ & 7.6 & $6.2-9.3$ & $4.0-9.4$ & 88 & $86-89$ & $84-91$ \\
\hline BDE-47 & 4.3 & $3.2-5.6$ & $1.2-14$ & 2.5 & $1.4-4.5$ & $0.70-45$ & 4.5 & $2.5-7.9$ & $1.8-16$ & 8.4 & $5.2-14$ & $4.8-36$ \\
\hline BDE-99 & 4.6 & $3.8-5.5$ & $2.5-10$ & 1.8 & $1.1-3.2$ & $0.35-18$ & 1.8 & $0.88-3.8$ & $0.67-15$ & 3.0 & $1.9-4.7$ & $1.4-7.9$ \\
\hline BDE-100 & 1.6 & $1.3-2.0$ & $0.65-5.6$ & 0.80 & $0.45-1.4$ & $0.23-17$ & 1.2 & $0.56-2.6$ & $0.40-8.1$ & 2.3 & $1.3-4.0$ & $1.2-12$ \\
\hline BDE-153 & 5.0 & $4.0-6.1$ & $2.5-10$ & 6.5 & $5.0-8.4$ & $3.3-15$ & 1.1 & $0.53-2.2$ & $0.53-11$ & 1.2 & $0.86-1.6$ & $0.67-2.4$ \\
\hline BDE-154 & 5.0 & $4.0-6.3$ & $1.9-10$ & 3.4 & $2.0-5.8$ & $0.54-16$ & 3.1 & $1.3-7.4$ & $1.3-19$ & 4.0 & $2.0-7.8$ & $1.6-19$ \\
\hline BDE-209 & $<0.27^{\mathrm{a}}$ & - & - & 1.2 & $0.39-3.4$ & $<0.27^{\mathrm{a}}-62$ & $<0.27^{\mathrm{a}}$ & - & - & $<0.27^{\mathrm{a}}$ & - & - \\
\hline$\Sigma$ PBDE* & $21^{\mathrm{a}}$ & $18-25$ & $11-42$ & 16 & $11-24$ & $5.8-110$ & 11 & $6.1-22$ & 4.7-68 & 19 & $12-30$ & $11-78$ \\
\hline BB-153 & 11 & $8.2-14$ & $3.7-51$ & 17 & $12-23$ & $6.2-44$ & 0.76 & $0.29-1.9$ & $0.26-2.6$ & 1.1 & $0.52-2.3$ & $0.34-3.3$ \\
\hline
\end{tabular}

$* \Sigma \mathrm{PBDE}=\mathrm{BDE}-47, \mathrm{BDE}-99, \mathrm{BDE}-100, \mathrm{BDE}-153$ and BDE-154

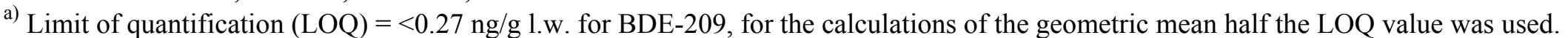


Table 3. Concentrations (ng/g lipid weight) of HCB, DDE, DDT and 10 PCB congeners in egg, muscle and subcutaneous fat from fulmars collected at the Faroe Islands: the geometric mean (GM), $95 \%$ confidence interval (c.i.) and ranges are given.

\begin{tabular}{|c|c|c|c|c|c|c|c|c|c|c|c|c|}
\hline & \multicolumn{3}{|c|}{$\begin{array}{l}\text { Fulmar egg } \\
\qquad(\mathrm{n}=19)\end{array}$} & \multicolumn{6}{|c|}{ Fulmar muscle } & \multicolumn{3}{|c|}{$\begin{array}{c}\text { Fulmar subcutaneous fat } \\
\text { Juvenile }(n=9)\end{array}$} \\
\hline & GM & $95 \%$ c.i. & range & GM & 95\% c.i. & range & GM & 95\% c.i. & range & GM & $95 \%$ c.i. & range \\
\hline CB-105 & 190 & $160-230$ & $110-360$ & 340 & $280-420$ & $160-540$ & 31 & $21-45$ & $21-66$ & 22 & $16-31$ & $15-48$ \\
\hline CB-118 & 810 & $660-990$ & $440-1700$ & 1400 & $1200-1700$ & $620-2400$ & 89 & $62-130$ & $42-180$ & 100 & $71-160$ & $58-230$ \\
\hline CB-128/CB-167 & 210 & $160-260$ & $100-450$ & 440 & $360-530$ & $240-720$ & 26 & $19-38$ & $17-61$ & 19 & $14-27$ & $11-40$ \\
\hline CB-138 & 850 & $680-1100$ & $390-2100$ & 1700 & $1400-2100$ & $750-2900$ & 160 & $100-250$ & $88-380$ & 160 & $96-280$ & $65-450$ \\
\hline CB-153 & 2500 & 1900-3300 & $1200-7500$ & 4700 & $3700-5800$ & $2200-9200$ & 230 & $160-330$ & $120-470$ & 340 & $210-550$ & $130-760$ \\
\hline CB-156 & 170 & $130-210$ & $86-320$ & 330 & $260-400$ & $160-630$ & 19 & $11-37$ & $13-41$ & 13 & $9.3-19$ & $7-25$ \\
\hline CB-170 & 440 & $340-580$ & $200-1400$ & 900 & $710-1100$ & $400-1800$ & - & - & - & 32 & $22-48$ & $15-66$ \\
\hline CB-180 & 1300 & $970-1800$ & $600-4200$ & 2500 & $1900-3200$ & $1000-5300$ & 130 & $84-200$ & $58-260$ & 110 & $64-170$ & $42-270$ \\
\hline CB-183 & 200 & $150-260$ & $86-640$ & 430 & $350-540$ & $190-830$ & 26 & $13-50$ & $9-100$ & 17 & $12-26$ & $8-37$ \\
\hline 乏PCB* & 6800 & $5200-8700$ & $3300-18000$ & 13000 & $10000-16000$ & $5800-24000$ & 740 & $540-1000$ & $400-1400$ & 880 & $560-1400$ & $380-2100$ \\
\hline HCB & 330 & $260-400$ & $74-580$ & 250 & $180-350$ & $92-590$ & 49 & $26-92$ & $16-100$ & 25 & $22-140$ & $15-100$ \\
\hline 4,4'-DDE & 2800 & $2100-3600$ & $1000-7000$ & 7100 & $4700-11000$ & $1700-20000$ & 530 & $320-900$ & $260-1800$ & 610 & $340-1100$ & $230-2000$ \\
\hline 4,4'-DDT & 230 & $200-290$ & $110-450$ & 240 & $150-580$ & $51-1200$ & 37 & $20-84$ & $18-110$ & 83 & $47-140$ & $41-320$ \\
\hline
\end{tabular}

$* \Sigma \mathrm{PCB}=\mathrm{CB}-105, \mathrm{CB}-118, \mathrm{CB}-128 / \mathrm{CB}-167, \mathrm{CB}-138, \mathrm{CB}-153, \mathrm{CB}-156, \mathrm{CB}-170, \mathrm{CB}-180$ and CB-183. 


\section{Results}

The concentrations of six PBDE congeners in fulmar eggs, muscle, and fat are given as a geometric mean, 95\% confidence interval, and ranges, along with the $\Sigma$ PBDE (sum of BDE47, BDE-99, BDE-100, BDE-153 and BDE-154) in Table 2. The concentrations are reported on a lipid weight basis. When comparing the $\Sigma$ PBDE concentrations determined in the eggs from year 2000 and year 2001, no significant difference is found. The geometric mean $\Sigma$ PBDE concentration for each year was $22 \mathrm{ng} / \mathrm{g} \mathrm{l.w}$. and $21 \mathrm{ng} / \mathrm{g} \mathrm{l.w.,} \mathrm{respectively.} \mathrm{The}$ concentrations of BB-153, in the different samples, are also given in Table 2. The geometric mean concentration of BDE-47, BDE-99, BDE-100, BDE-153, BDE-154, and BB-153 are graphically presented in Fig. 1 on a molar basis (pmol/g l.w.) in the fulmar matrices analysed.

The concentrations, reported as geometric mean, 95\% confidence interval, and ranges on a lipid weight basis, of the 10 major PCB congeners and the $\Sigma$ PCB (sum of detected PCB congeners), HCB, 4,4'-DDE, and 4,4'-DDT are presented in Table 3. The $\Sigma \mathrm{PCB}$ geometric mean concentration in the egg samples collected in May 2001 (5300 ng/g l.w.) is somewhat lower compared to the preceding year $(8800 \mathrm{ng} / \mathrm{g}$ l.w.). On the other hand, the $\Sigma$ PCB range is slightly wider for the samples collected in May 2001 compared to the samples collected in May 2000 (i.e. 3300-18000 ng/g 1.w. and 3500-13000 ng/g 1.w., respectively). The $\Sigma$ PCB concentration range in the muscle from adult fulmars $(5800-24000 \mathrm{ng} / \mathrm{g} 1 . \mathrm{w}$.) was similar to the $\Sigma$ PCB concentration ranges in the eggs. The lipid amount in muscle varied between juvenile and adult fulmars, with values of $7.8 \%$ and $4.3 \%$ lipid, respectively. Both muscle and subcutaneous fat from the juvenile fulmars showed significantly lower $\Sigma$ PCB concentrations, while the $\Sigma$ PBDE concentrations did not differ significantly between the adult and the juvenile fulmars.

\section{Discussion}

The PBDE concentrations in fulmar and fulmar eggs from the Faroe Islands are lower than those determined in other bird eggs, studied so far (Lindberg et al., 2004; Norstrom et al., 2002; Sellström et al., 2003; Vorkamp et al., 2004b). For example, in guillemot eggs from the Baltic Sea and in guillemot from East Greenland, the PBDE concentrations are about 5 times higher than the levels found in the Faroese fulmar eggs. In herring gull eggs from the Great Lakes, the PBDE concentrations are two - three orders of magnitude higher (Norstrom et al., 2002; Sellström et al., 2003; Vorkamp et al., 2004b). This implies a yet limited contamination of PBDEs in the Faroe Islands area. The $\Sigma$ PBDE concentrations were about $2-5 \%$ of the $\Sigma$ PCB concentration in the herring gull eggs and in the black guillemot eggs (Norstrom et al., 2002; Vorkamp et al., 2004b), while they were only $0.3 \%$ in the Faroese fulmar eggs. Subcutaneous fat and muscle from the juvenile fulmars also indicating low PBDE concentrations at the Faroe Islands. However, 5 PBDE concentrations were $2 \%$ and $1.6 \%$ of the $\Sigma$ PCB concentration in juvenile fulmar fat and muscle, respectively (Table 2 and 3 ). The lower $\Sigma \mathrm{PBDE} / \Sigma \mathrm{PCB}$ ratio in the fulmar egg may indicate different efficiency in transfer from the bird to egg, of these two classes of contaminants. The typical PBDE congener concentration pattern previously documented for wildlife has revealed BDE-47 as the most abundant PBDE congener followed by BDE-99, BDE-100, BDE-153 and BDE-154 as seen in guillemot eggs from the Baltic, black guillemot from Greenland and herring gull eggs from the Great Lakes (Norstrom et al., 2002; Sellström et al., 2003; Vorkamp et al., 2004b). In muscle and subcutaneous fat from juvenile fulmars (Fig. 1 and Table 2) BDE-47 is the dominating congener also in this study. However, in the juvenile fulmars the relative PBDE pattern is slightly different, BDE-47 is followed by BDE-154 instead of BDE-99. In contrast, almost all muscle samples from adult fulmars showed a higher relative contribution of BDE- 
153 compared to BDE-47 (Fig. 1 and Table 2). This difference in PBDE pattern between adult and juvenile fulmars is difficult to explain and we do not want to speculate at this stage.

The BB-153 concentrations follows the PCBs, 4,4'-DDT, 4,4'-DDE and HCB with higher concentrations in the adult than in the juvenile bird (Table 3). The PCB concentrations in this study are in a similar range as has previously been reported in fulmars from the Faroese, by Dam et al. (2001). The CB-138, CB-153 and CB-180 concentrations are the highest among all PCB congeners and similar to 4,4'-DDE, i.e. in the low ppm range. HCB and 4,4'-DDT concentrations are almost $10 \%$ of the most abundant contaminants (Table 3 ). The fulmars are highly contaminated with the PCBs and DDE while the PBDE concentrations over all seems moderately high. These data are in agreement with in general lower contamination of PBDEs in the environment where these fulmars live and hatch compared to wildlife exposure in the Baltic Sea and the Great Lakes areas (Norstrom et al., 2002; Sellström et al., 2003). Also the BB-153 follow the same pattern as the PCB-congners and DDTs with a BB-153/ $\mathrm{PBDDE}$ ratio of about $7 \%$ in the juvenile bird compared to $110 \%$ in the adult bird (c.f. Table 2 and 3). It is notable that the PBDE concentrations did not differ significantly between the adult and the juvenile fulmars (Fig. 1) while the PCB concentrations did. This may indicate that the fulmars are exposed to the PBDEs more recently than to PCBs and PBBs. Possibly the adult fulmars have been exposed to PCBs and PBBs when migrating along the Atlantic coastlines south of the Faroe Islands.

As shown here and by others (Ikonomou et al., 2002; Lindberg et al., 2004; Olsson et al., 2000; Vorkamp et al., 2004b) the location of the sampling site and where the species roam do have a major influence on the PBDE, PCB and PBB concentrations. Similarly, as shown in a study on herring gulls, a colony from the Great Lakes near a heavily industrial area had higher PBDE concentrations compared to other colonies at remote locations (Norstrom et al., 2002).

BDE-209 was detected in almost all muscle samples from the adult fulmar, but neither in the egg nor in the juvenile bird (Table 2). Peregrine falcon eggs from Sweden were reported to contain BDE-209 at concentrations about 50 times higher than those observed in the fulmar muscle (Lindberg et al., 2004). It can not be excluded that the concentrations and pattern of BDE-209 and BDE-153 is influenced by BDE-209 metabolism but this statement still need to be proven.

Earlier epidemiological studies have shown that Faroese residents may be highly exposed to PCBs, probably due to a traditional diet that includes whale and seabirds (Fängström et al., 2002; Fängström et al., 2004; Grandjean et al., 1995). In a birth cohort from 1987, relatively high levels of PCBs were detected in four pools of human milk samples, with ranges between 1.9 and $2.5 \mu \mathrm{g} / \mathrm{g}$ 1.w (Grandjean et al., 1995). In another cohort from 1994, $\mathrm{PCB}$ and $\mathrm{OH}-\mathrm{PCB}$ concentrations were determined in serum from pregnant women, with ranges of $0.15-22 \mu \mathrm{g} / \mathrm{g} 1 . \mathrm{w}$. and $0.02-1.8 \mu \mathrm{g} / \mathrm{g} 1 . \mathrm{w}$., respectively. The concentration ranges were very wide and there were considerable difference in concentration between the lowest and the highest detected concentrations, which probably reflects the variations in diet (Fängström et al., 2002). The PCB concentration in the fulmar egg and muscle are rather high and in the same range as seen in pilot whale blubber (mean $13 \mu \mathrm{g} / \mathrm{g} 1 . \mathrm{w}$., range 4.7-24 $\mu \mathrm{g} / \mathrm{g}$ ). The geometric mean $\Sigma$ PCB concentration in the fulmar muscle is $13 \mu \mathrm{g} / \mathrm{g} 1 . \mathrm{w}$., which is approximately twice the concentration in the egg, with a geometric mean of $6.8 \mu \mathrm{g} / \mathrm{g} 1 \mathrm{w}$. Human exposure via food is dependent on the lipid content of the food items. In the fulmar egg, the lipid amount (10\%) is higher than in the muscle $(4.3 \%)$. This difference makes the exposure contribution on a fresh weight basis almost the same (Fig. 2). The present study shows that the OHS exposure contribution from fulmar and fulmar egg should not be neglected as a potential source for these compounds. For some Faroese, the consumption of fulmars might represent a considerable contribution to their total PCB exposure. Every year 
about 15000 - 20000 adult, 40000 - 100000 juvenile fulmars, and 5000 - 10000 fulmar eggs are caught and consumed at the Faroe Islands. In a study from Quebec, it was shown that the PCB exposure in fishermen was significantly associated with the seabird egg consumption, and only a weak correlation was observed to fish consumption (Ryan et al., 1997).

Neither the fulmar nor the pilot whale are stationary species in the Faroe Islands area and both are rather common species belonging to the North western Atlantic. Despite the great distance to industrial sources of OHS, PBDEs are present in marine wildlife, as well as traditional OHS. It must now be considered evident that this group of brominated flame retardants - the PBDEs - constitute ubiquitous environmental pollutants.

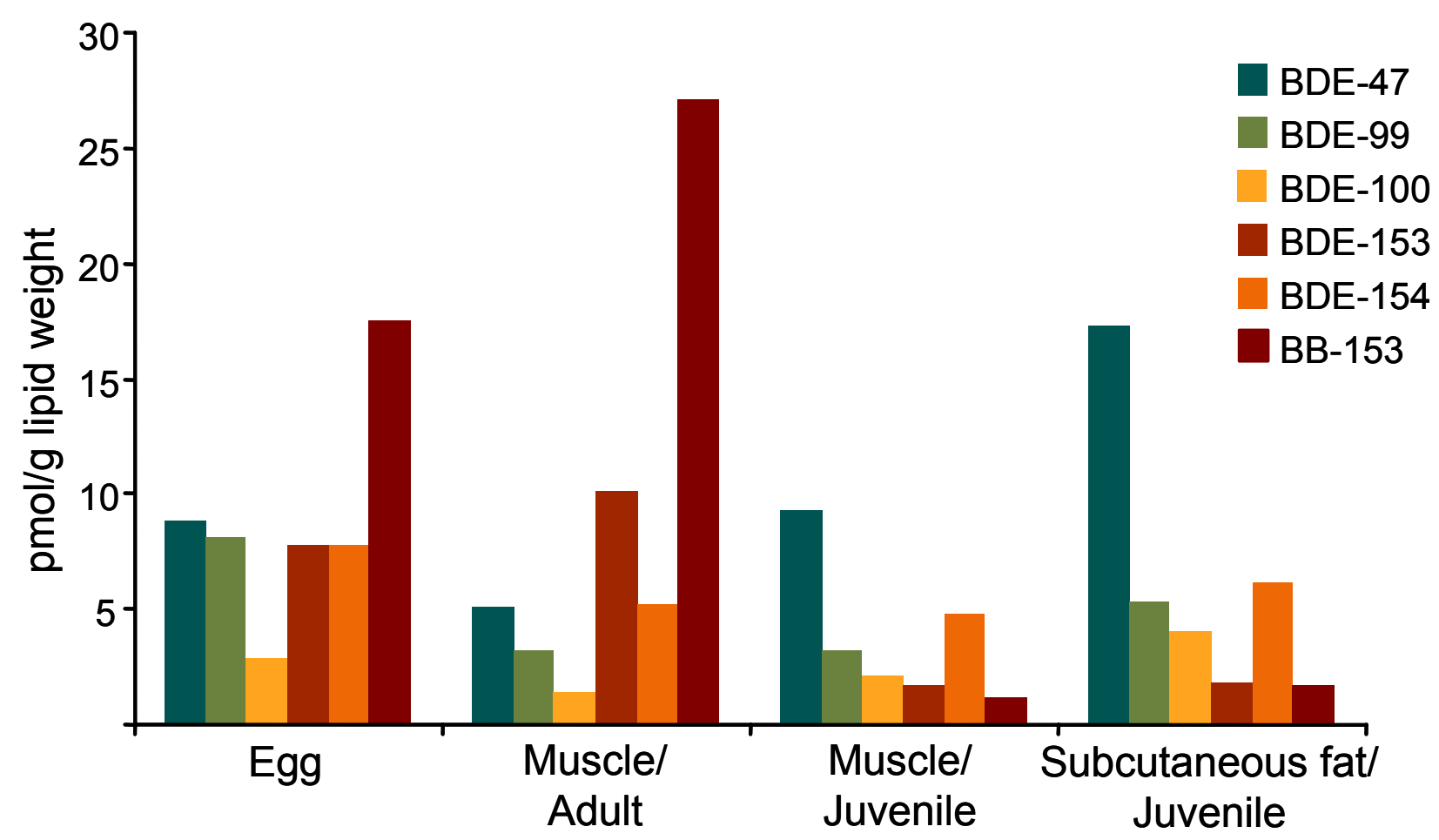

Figure 1. The geometric mean concentration of BDE-47, BDE-99, BDE-100, BDE-153, BDE-154, and BB-153 (pmol/g lipid weight) in fulmar eggs $(\mathrm{n}=19)$, adult muscle $(\mathrm{n}=14)$, juvenile muscle $(n=9)$, and juvenile subcutaneous fat $(n=9)$ samples are given. 


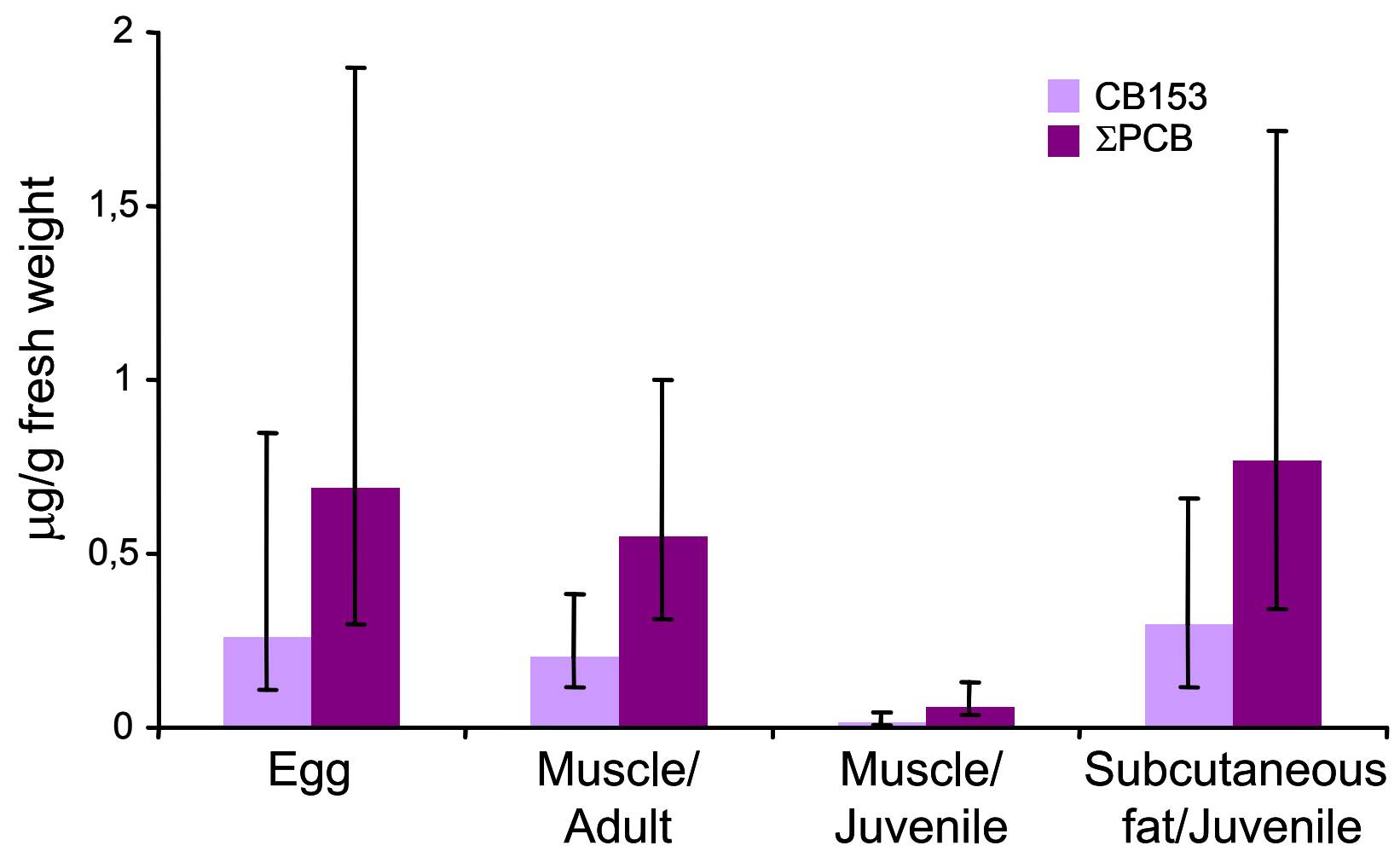

Figure 2. The geometric mean concentration of CB-153 and $\Sigma$ PCB (sum of detected PCB congeners) on a fresh weight basis $(\mu \mathrm{g} / \mathrm{g})$ are given for fulmar eggs $(\mathrm{n}=19)$, adult muscle $(n=14)$, juvenile muscle $(n=9)$ and juvenile subcutaneous fat $(n=9)$. The bars indicate minimum and maximum concentrations. 


\section{Acknowledgement}

We are grateful to Anna Roos and Mats Hjelmberg from the Contaminant Research Group at the Swedish Museum of Natural History for assistance in preparing the egg, muscle, and subcutaneous fat samples. We also want to thank "'havundersøgelsesskibet' Magnus Heinason" from the Faroese Fiskeriundersøgelser - Faroese Fisheries Laboratory for collecting the 10 adult fulmars in November 2000. The project was financially supported by grants from the EU R\&D programme, Anemone (QLK4-CT-2001-00186)

\section{References}

Ballschmiter, K., Mennel, A. and Buyten, J., 1993. Long chain alkyl-polysiloxanes as non-polar stationary phases in capillary gas chromatography, Fresenius J. Anal. Chem. 346, pp. 396-402.

Bignert, A., Litzén, K., Odsjö, T., Olsson, M., Persson, W. and Reutergårdh, L., 1995. Time-related factors influence the concentrations of sDDT, PCBs and shell parameters in eggs of Baltic guillemot (Uria aalge), 1861-1989, Environ. Pollut. 89, pp. 27-36.

Braune, B. M., Donaldson, G. M. and Hobson, K. A., 2001. Contaminant residues in seabird eggs from the Canadian Arctic. Part I. Temporal trends 1975-1998, Environ. Pollut. 114, pp. 39-54.

Dam, M. and Bloch, D., 2000. Screening of Mercury and Persistent Organochlorine Pollutants in Long-Finned Pilot Whale (Globicephala melas) in the Faroe Islands, Mar. Pollut. Bull. 40, pp. 1090-1099.

Dam, M., Mikkelsen, B., and Jensen, J.-K. Orgnochlorinated poolutants in fulmars from the Faroe Islands. 2001. Food and Envrironmental Agency.

de Wit, C., 2002. An overview of brominated flame retardants in the environment, Chemosphere 46, pp. 583-624.

Esmen, N. and Hammond, Y., 1977. Log-Normality of Environmental Sampling Data., J. Environ. Sci. Health A12, pp. 29-41.

Fängström, B., Athanasiadou, M., Athanassiadis, I., Weihe, P. and Bergman, Å., 2005. Hydroxylated PCB metabolites in Non-hatched Fulmar Eggs from the Faroe Islands, Ambio 34(3), pp. 184-7.

Fängström, B., Athanasiadou, M., Grandjean, P., Weihe, P. and Bergman, Å., 2002. Hydroxylated PCB metabolites and PCBs in serum from pregnant Faroese women, Environ. Health Perspect. 110, pp. 895-899.

Grandjean, P., Weihe, P., Needham, L. L., Burse, V. W., Patterson, D. G. Jr., Sampson, E. J., Jorgensen, P. J. and Vahter, M., 1995. Relation of a seafood diet to Mercury, Selenium, Arsenic and Polychlorinated Biphenyl and other organochlorine concentrations in human milk, Environ. Res. 71, pp. 29-38.

Hites, R. A., 2004. Polybrominated Diphenyl Ethers in the Environment and in People: A MetaAnalysis of Concentrations, Environ. Sci. Technol. 38, pp. 945-956.

Ikonomou, M. G., Rayne, S. and Addison, R. F., 2002. Exponential increases of the brominated flame retardants, polybrominated diphenyl ethers, in the Canadian arctic from 1981 to 2000, Environ. Sci. Technol. 36, pp. 1886-1892.

Jensen, S., Reutergårdh, L. and Jansson, B., 1983. Analytical methods for measuring organochlorines and methyl mercury by gas chromatography, FAO Fish. Tech. Pap. 212, pp. 21-33.

Law, R. J., Alaee, M., Allchin, C. R., Boon, J. P., Lebeuf, M., Lepom, P. and Stern, G. A., 2003. Levels and trends of polybrominated diphenylethers and other brominated flame retardants in wildlife, Environ. Int. 29, pp. 757-770.

Lindberg, P., Sellström, U., Häggberg, L. and de Wit, C. A., 2004. Higher brominated diphenyl ethers and hexabromocyclododecane found in eggs of peregrine falcons (Falco peregrinus) breeding in Sweden, Environ. Sci. Technol. 38, pp. 93-96.

Lindström, G., Wingfors, H., Dam, M. and van Bavel, B., 1999. Identification of 19 polybrominated diphenyl ethers (PBDEs) in long-finned pilot whale (Globicephala melas) from the Atlantic, Arch. Environ. Contam. Toxicol. 36, pp. 355-363. 
Marsh, G., Hu, J., Jakobsson, E., Rahm, S. and Bergman, Å., 1999. Synthesis and characterization of 32 polybrominated diphenyl ethers, Environ. Sci. Technol. 33, pp. 3033-3037.

Norstrom, R. J., Simon, M., Moisey, J., Wakeford, B. and Weseloh, D. V. C., 2002. Geographic distribution (2000) and temporal trends (1981-2000) of brominated diphenyl ethers in Great Lakes herring gull eggs, Environ. Sci. Technol. 36, pp. 4783-4789.

Olsson, A., Ceder, K., Bergman, A. and Helander, B., 2000. Nestling blood of the white-tailed Sea Eagle (Haliaeetus albicilla) as an indicator of territorial exposure to organohalogen compounds - An evaluation, Environ. Sci. Technol. 34, pp. 2733-2740.

Ryan, J. J., Dewailly, E., Gilman, A., Laliberté, C., Ayotte, P. and Rodrigue, J., 1997. Dioxin-Like Compounds in Fishing People from the Lower North Shore of the St. Lawrence River, Québec, Canada, Arch. Environ. Health 52, pp. 309-316.

Sellström, U., Jansson, B., Kierkegaard, A., de Wit, C., Odsjö, T. and Olsson, M., 1993. Polybrominated diphenyl ethers (PBDE) in biological samples from the Swedish environment, Chemosphere 26, pp. 1703-1718.

Sellström, U., Bignert, A., Kierkegaard, A., Häggberg, L., de Wit, C. A., Olsson, M. and Jansson, B., 2003. Temporal trend studies on tetra- and pentabrominated diphenyl ethers and hexabromocyclododecane in guillemot egg from the Baltic Sea, Environ. Sci. Technol. 37, pp. 5496-5501.

Sjödin, A., Jones, R. S., Lapeza, C., Focant, J.-F., Wang, R., Turner, W. E., Needham, L. L., and Patterson, D. G. Jr. Retroperspective time trend study of brominated flame retardants and polychlorinated biphenyls in human serum from various regions of the United States, 18852002. 61, 1-4. 2003. Boston, MA, USA. Organohalogen compounds.

Sokal, R. R. and Rohlf, F. J., Biometry. Freeman, New York (1981).

ter Schure, A. F. H., Larsson, P., Agrell, C. and Boon, J. P., 2004. Atmospheric Transport of Polybrominated Diphenyl Ethers and Polychlorinated Biphenyls to the Baltic Sea, Environ. Sci. Technol. 38, pp. 1282-1287.

Vorkamp, K., Christensen, J. H., Glasius, M. and Rigert, F., 2004a. Persistent halogenated compounds in black guillemots ( Cepphus grylle) from Greenland-levels, compound patterns and spatial trends, Mar. Pollut. Bull. 48, pp. 111-121.

Vorkamp, K., Christensen, J. H. and Riget, F., 2004b. Polybrominated diphenyl ethers and organochlorine compounds in biota from the marine environment of East Greenland, Sci. Total Environ. 331, pp. 143-155.

Wania, F., 2003. Assessing the Potential of Persistent Organic Chemicals for Long-Range Transport and Accumulation in Polar Regions, Environ. Sci. Technol. 37, pp. 1344-1351.

Wania, F. and Mackay, D., 1996. Tracking the Distribution of Persistent Organic Pollutants, Environ. Sci. Technol. 30, pp. 390-396.

Örn, U., Eriksson, L., Jakobsson, E. and Bergman, Å., 1996. Synthesis and characterization of polybrominated diphenyl ethers - unlabelled and radiolabelled tetra-, penta- and hexabromodiphenyl ethers, Acta Chem. Scand. 50, pp. 802-807. 